\title{
High volume image-guided injections and structured rehabilitation improve greater trochanter pain syndrome in the short and medium term: a combined retrospective and prospective case series
}

\author{
Sarah Morton 1 \\ Otto Chan ${ }^{2}$ \\ Jessica Price ${ }^{1}$ \\ Melanie Pritchard ${ }^{2}$ \\ Tom Crisp ${ }^{1,2}$ \\ John D. Perry ${ }^{1,2}$ \\ Dylan Morrissey 1,2,3
}

1 Centre for Sports and Exercise Medicine, William Harvey Research Institute, Bart's and the London School of Medicine and Dentistry, Queen Mary University of London, Mile End Hospital, UK

2 BMI London Independent Hospital, UK

3 Physiotherapy Department, Bart's Health NHS Trust, London, UK

Corresponding author:

Dylan Morrissey

Centre for Sports and Exercise Medicine, William Harvey Research Institute, Bart's and the London School of Medicine and Dentistry, Queen Mary University of London, Mile End Hospital

Bancroft road

E1 4DG London, UK

E-mail: d.morrissey@qmul.ac.uk

\section{Summary}

Background: the aim of this study was to measure the effects of high volume image-guided injections and structured rehabilitation (HVIGI\&SR) for greater trochanter pain syndrome (GTPS).

Methods: 31 consecutive subjects were recruited (23 retrospectively; 8 prospectively) over 5 months. GTPS was diagnosed based on history and examination findings, alongside radiological examination. The HVIGI used a 22-gauge spinal needle to administer $10 \mathrm{ml}$ of $\mathbf{0 . 5 \%}$ Marcaine and $50 \mathrm{mg}$ hydrocortisone just deep to the periosteum underlying the gluteal tendon insertion under ultrasound guidance, followed by structured rehabilitation. A visual analogue scale (VAS) for pain was used as the main outcome measure.

Results: the mean VAS improved from $81.7 \mathrm{~mm}$ $( \pm 17.6)$ to $42.3 \mathrm{~mm}( \pm 28.3),(p<0.05)$ in the prospective subjects at a mean of 6 weeks, considered clinically significant. In the retrospective subjects the mean VAS had improved from $74.6( \pm 10.9) \mathrm{mm}$ to $38.2( \pm 31.2) \mathrm{mm}$ at two weeks $(p<0.01)$ and 31.3
$( \pm 27.6) \mathrm{mm}$ at the final time point, a mean of 60 weeks $(p<0.01)$. The Hip and Groin Outcome Score in the prospective group showed a non-significant increase from 173.2 to $296.1(p=0.12)$.

Conclusion: HVIGI\&SR should be considered when short- and medium-term pain-relieving treatment for GTPS is required. Controlled studies are warranted to fully establish effectiveness, and assess long term effects.

Level of evidence: case series.

KEY WORDS: injection, greater trochanter pain syndrome, ultrasound, VAS scale.

\section{Introduction}

Of the hip complaints presenting to primary care, 10$20 \%$ are thought to be due to greater trochanter area pain ${ }^{1}$. Within the US military an incidence of 2.03 per 1000 person-years was found, with a significantly greater incidence in women compared to men². The causes of trochanteric pain are numerous including trochanteric bursitis, tendinopathy, muscle tears, iliotibial band disorders and bursalin flammation ${ }^{3-5}$. As a result of this, and the difficulty in making a precise diagnosis, the term Greater Trochanteric Pain Syndrome (GTPS) has been implemented in clinical practice ${ }^{6}$.

The majority of patients with GTPS are managed conservatively and respond well to therapies that include progressive exercise and education ${ }^{6}$. Corticosteroid injections are also commonly used as a non-operation option with reported responses ranging from $60-100 \% 7$. However the literature also suggests that the longevity of the corticosteroid injection effect is limited and is less effective than home training or shock wave therapy ${ }^{8}$. Indeed the site of the corticosteroid injection may be important, as one study suggested that greater trochanteric bursa injections are superior to deep to gluteus medius bursa injections ${ }^{9}$. A recent review suggested that despite its common use in clinical practice there are very few studies on its effectiveness, and also minimal evidence comparing blind injections to image guided injections ${ }^{7}$. Surgery is used in very recalcitrant cases, however the evidence base does not allow definitive conclusions about the best form of treatment for different presentations to be made with confidence ${ }^{6}$. Many people suffer recalcitrant and recurrent problems with significant impact on health ${ }^{10}$; indeed the effect of greater trochanteric pain syndrome on a patient's life has been found by Fearon et al. to be similar in some respects to late stage hip osteoarthritis ${ }^{11}$. 
High volume image-guided injections with structured rehabilitation (HVIGI\&SR) have been shown to be effective in improving pain and function for both Achilles and patellar tendinopathy ${ }^{12-14}$. More recently they have been shown to be effective in the short term reduction of pain and improvement in function in shoulder impingement syndrome, another syndrome encompassing many diagnoses ${ }^{15}$. The mechanism behind the effect of the HVI$\mathrm{Gl}$ is not well understood but Chan et al. ${ }^{13}$ hypothesise that there is disruption of the neovascularisation seen in tendinopathy. In shoulder impingement syndrome, which encompasses other non-tendinopathy conditions. Morton et al. ${ }^{15}$ hypothesise that there is disruption of the scar tissue or separation of tissues, although it is recognised that more work is required to confirm this. Therefore, the aim of this research was to provide preliminary evidence to clinicians about the short- and medium-term treatment effectiveness of HVIGI\&SR for GTPS, using both retrospective and prospective data.

Table 1. Inclusion and Exclusion Criteria.

\section{Materials and methods}

\section{Subjects}

Every patient $(n=8)$ attending one specialist MSK radiology clinic over a five month period who met the inclusion and exclusion criteria (Tab. 1) were recruited prospectively, completing a visual analogue scale (VAS) for pain and the Hip and Groin Outcome Score (HAGOS) at the appointment and then again at six weeks postHVIGI\&SR ${ }^{16}$. Retrospective patients $(n=23)$ were identified from a database covering the previous two years and sent the above questionnaires. Ethical clearance was obtained from Queen Mary University of London Ethics of Research Committee and consent was obtained via the questionnaire. The subjects' characteristics can be seen in Table 2. The research followed the guidelines as laid out by Padulo et al. ${ }^{17}$. Please see Appendix 1 for copies of the questionnaire (both retrospec-

\begin{tabular}{ll}
\hline Inclusion & Exclusion \\
\hline $18-80$ years & $\begin{array}{l}\text { Another cause for hip pain is suspected } \\
\text { Injection contraindicated e.g. allergy to the content }\end{array}$ \\
$\begin{array}{l}\text { Clinical diagnosis of GTPS } \\
\text { Local tenderness over greater trochanter }\end{array}$ \\
$\begin{array}{l}\text { Radiological examination to rule out alternative causes } \\
\text { for their lateral hip pain such as osteoarthritis } \\
\text { Recalcitrant to rehabilitation }\end{array}$
\end{tabular}

Table 2. Subject Characteristics.

\begin{tabular}{|c|c|c|}
\hline & Retrospective subjects & Prospective subjects \\
\hline Mode age range & $46-55$ & $56-65$ \\
\hline Gender (M:F) & $2: 12$ & $3: 4$ \\
\hline \multicolumn{3}{|l|}{ Level of sport/activity } \\
\hline No activity: & 4 & 0 \\
\hline Recreational: & 7 & 5 \\
\hline Local club: & 0 & 2 \\
\hline Elite national/international (amateur): & 1 & 0 \\
\hline Elite national/international (prof): & 2 & 0 \\
\hline \multirow[t]{3}{*}{ Side of injection } & Right: 8 & Right: 4 \\
\hline & Left: 5 & Left: 3 \\
\hline & Bilateral: 1 & Bilateral: 0 \\
\hline Mean number of clinicians seen & 4.38 & 2.86 \\
\hline \multicolumn{3}{|l|}{$\%$ of subjects that have undergone investigations: } \\
\hline Blood tests: & $38 \%$ & $14 \%$ \\
\hline XR: & $54 \%$ & $71 \%$ \\
\hline Magnetic Resonance Imaging (MRI): & $69 \%$ & $57 \%$ \\
\hline CT: & $8 \%$ & $0 \%$ \\
\hline US: & $100 \%$ & $100 \%$ \\
\hline Other: & $8 \%$ & $0 \%$ \\
\hline Mean length of symptoms prior to HVIGI\&SR: & $\begin{array}{l}3.09 \text { years } \\
\text { (1 data set unavailable) }\end{array}$ & 1.29 years \\
\hline \multicolumn{3}{|c|}{$\%$ of subjects that had undergone previous treatments: } \\
\hline Oral pain killers & $86 \%$ & $29 \%$ \\
\hline Topical pain killers & $43 \%$ & $0 \%$ \\
\hline Physiotherapy & $43 \%$ & $29 \%$ \\
\hline Steroid injection (singular) & $0 \%$ & $0 \%$ \\
\hline Steroid injection (multiple) & $14 \%$ & $14 \%$ \\
\hline
\end{tabular}


tive and prospective) and Appendix 2 for a copy of the HAGOS questionnaire.

\section{Procedure}

All ultrasound scanning and interventions were carried out by the same skilled MSK radiologist. The injection consisted of $10 \mathrm{ml} 0.5 \%$ Marcaine and $50 \mathrm{mg}$ hydrocortisone. The area of greatest pain over the greater trochanter was marked. A 22-gauge spinal needle was introduced just deep to the periosteum using an aseptic technique (Fig. 1). The injection was performed with ultrasound guidance using a $13 \mathrm{MHz}$ probe (Elegra; Siemens, Erlangen, Germany), but not real-time guidance.

\section{Structured rehabilitation}

Following the injection, the patients were reviewed by a consultant physiotherapist or his deputy, who prescribed a standardised structured rehabilitation programme. Patients were initially advised to have relative rest for 3 days and $400 \mathrm{mg}$ ibuprofen up to three times a day for the first three days as required, if not contraindicated. An exercise programme was developed that met their activity-specific targets. The primary intervention was educational, with advice given to avoid positions that put the gluteal tendons into compressive positions, such as postural advice to avoid lateral slouch standing and excessive adduction postures in sitting ${ }^{18,19}$. Non-impact cardiovascular exercise was advised if not already undertaken, optimally three times a week with an interval training component if tolerable. Assessment was based on the clinical examination principles outlined by Grimaldi (2011) and Reiman et al. $(2014)^{20,21}$.The specific exercise element focussed on developing isometric and concentric-eccentric endurance tolerance in weight bearing during the first two weeks of the rehabilitation programme; progressing to increased load tolerance over 4 weeks, with power and impact being included in the programme last and only to the level required for function ${ }^{19}$. Exercises were assessment based, but typically included hip extensor and abductor activation and endurance training alongside core body control exercise that focussed on lateral trunk control, as the hip abductors are recognised to be key in core stabilisation ${ }^{19}$. Adductor or horizontal plane rotation exercises were less commonly prescribed.

\section{Analysis}

The change in the VAS pain scale was used to assess pain effects. The HAGOS was used to describe hip-specific functions ${ }^{16}$. Data was analysed using SPSS (SPSS statistics version 20, IBM, USA). The data was found to be normally distributed. A paired ttest was used to analyse both the pre and post-injection VAS and HAGOS scores. Significance was set at $p<0.05$.

\section{Results}

Six of the eight prospective subjects completed the follow-up questionnaire. The mean follow-up time was 43.5 days. In the retrospective study fourteen of the 23 subjects completed the questionnaires, a total response rate of $63 \%$ in the retrospective group. Overall the response rate was $65 \%$. The mean time between the injection and completion of the questionnaire in the retrospective group was 60 weeks. Thirty-five per cent of all subjects had experienced pain for over 2 years prior to their attendance for HVIGI\&SR.

\section{VAS Pain Scale Results}

In the prospective study, the mean VAS scores were reduced from $81.7 \mathrm{~mm}( \pm 17.6)$ pre-injection to 42.3 $\mathrm{mm}( \pm 28.3)$, a change of $39.4 \mathrm{~mm}$, at a mean time of 43.5 days follow-up $(p=0.03)$, (Fig. 2$)$. In the retrospective study, the mean VAS also reduced from $74.6 \mathrm{~mm}( \pm 10.9)$ pre-HVIGI\&SR to $38.2( \pm 31.2) \mathrm{mm}$ at 2 weeks, which is both statistically and clinically significant $(p<0.01)$. The overall reduction in the VAS score of the retrospective group was a change of $43.3 \mathrm{~mm}$ from $74.6( \pm 10.9) \mathrm{mm}$ to $31.4( \pm 27.6) \mathrm{mm}$ at a mean time of 60 weeks $(p<0.01)$, showing a maintained reduction in the VAS score. $62 \%$ of retrospective subjects had returned to their normal level of activity at the mean follow up time of 60 weeks. Four out of the 8 prospective subjects reported that they

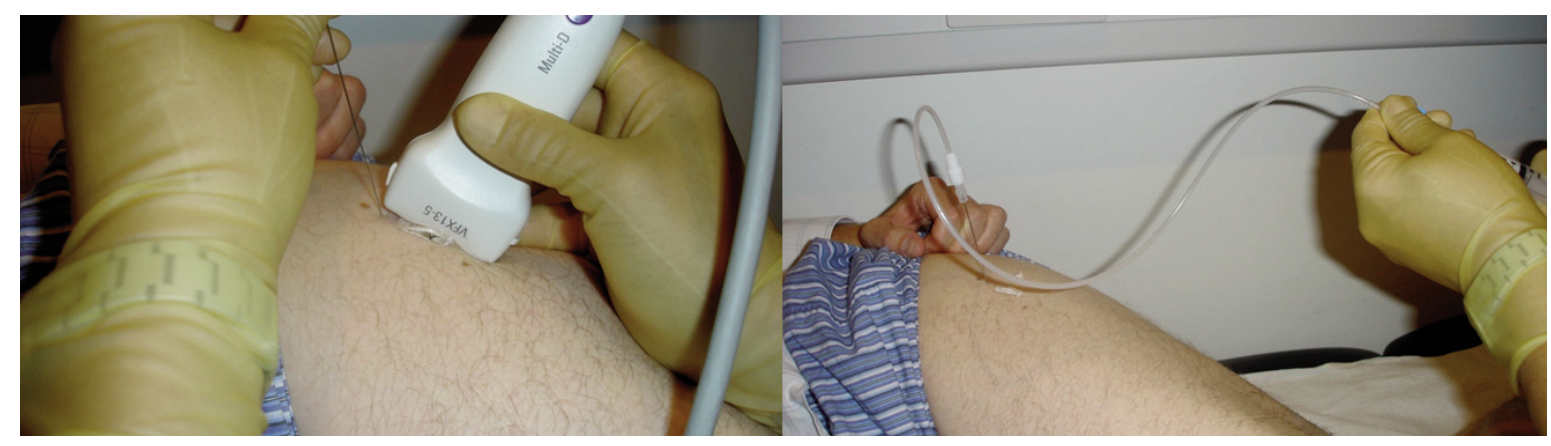

Figure 1. Insertion of the 22-spinal gauge needle under ultrasound guidance and administration of HVIGI. 
had returned to their normal levels of activity at the mean time of 43.5 days.

\section{Hip and Groin Outcome Score}

For the prospective group the mean HAGOS, for the six who completed the follow-up questionnaire, increased from $173.2( \pm 103.3)$ pre-HVIGI\&SR to 294.4 $( \pm 163.2)$ at follow-up, which was not statistically significant $(p=0.13)$. The majority of improvement occurred in the quality of life element of the questionnaire, which was statistically significant $(p=0.04)$. The changes for each element are shown in Figure 3.

Twenty five percent $(n=5)$ of all subjects reported short term pain as a side effect of the injection. One subject reported short term stiffness as a result of the injection. No other side effects were described or observed.

Of the fourteen retrospective subjects two went on to have surgery in the time period following their injection and prior to being followed up by this study (one had iliotibial band lengthening, the other unknown); one other subject had acupuncture. Of these sub-

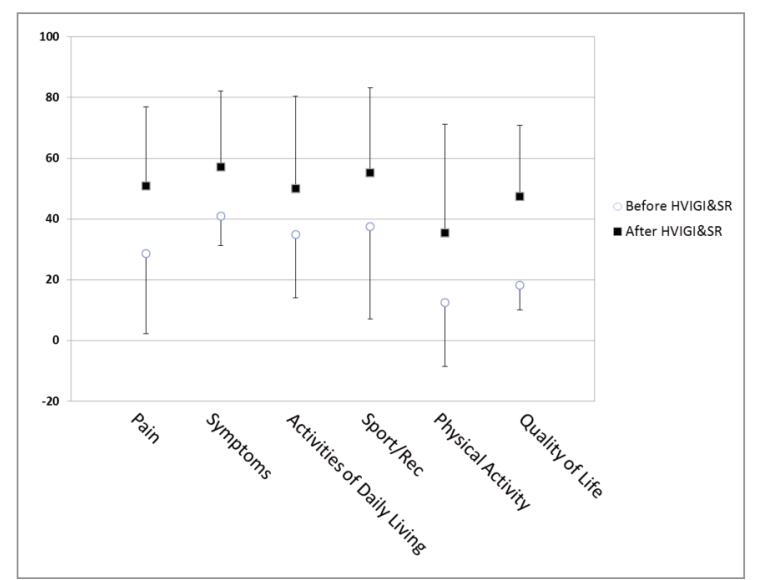

Figure 2. Mean change in each element of the HAGOS for the prospective patients.

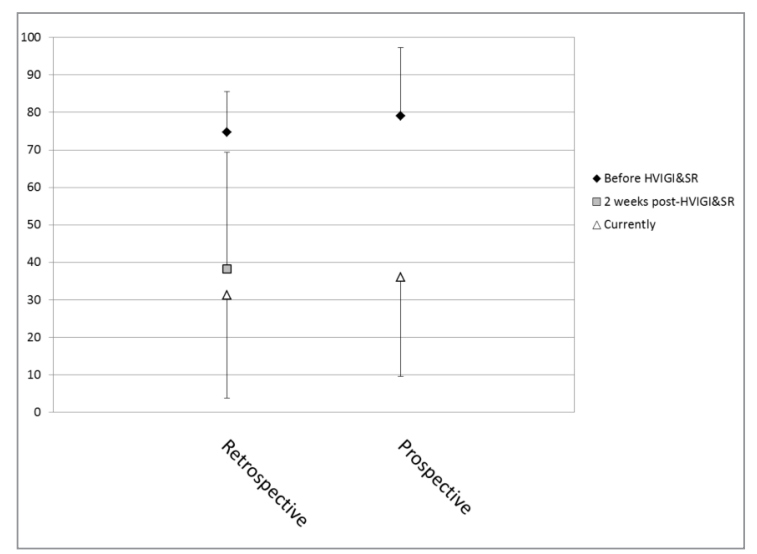

Figure 3. Mean change in VAS (mm) of pain for retrospective and prospective patients. jects all had had their pain for $>18$ months prior to the injection. None of the prospective subjects had any additional therapy in the time in which they were followed up.

\section{Discussion}

Both the retrospective and prospective groups showed a statistically significant reduction in pain following a HVIGI into the periosteum overlying the greater trochanter in patients with GTPS followed by structured rehabilitation. A reduction of $9 \mathrm{~mm}$ on the VAS pain scale is considered clinically significant in an acute pain setting and therefore the reduction of 43.3 $\mathrm{mm}$ for the retrospective group and $39.4 \mathrm{~mm}$ for the prospective group is likely to be considered a good clinical improvement in the presence of chronic symptoms ${ }^{22}$. These findings are also comparable to other treatments used in GTPS, including extracorporeal shock wave therapy 6,23 . Shbeeb et al. have found that a single local corticosteroid injection resulted in a greater than $60 \%$ improvement in the short and medium-term, which is similar to the $62 \%$ who had returned to their normal activity level in this study ${ }^{24}$. Rompe et al. showed that a home training regime showed the greatest long term improvement in comparison to corticosteroid injections, although in the short-term corticosteroid injections were most successful $^{8}$. It is therefore likely that the combination of both the HVIGI and the standard rehabilitation programme in this study will ensure patients benefit in the short term from the injection and, in the longer term, from the rehabilitation programme; longer follow up is required to confirm this.

The change observed in the HAGOS in the prospective group showed a trend towards significance ( $p$ $=0.13$ ), likely due to the small group size. There was a statistically significant $(p=0.04)$ improvement in the questions relating to quality of life, which is likely to be clinically important to those receiving any treatment. However, due to the small group size and inter-patient variability, no strong conclusions can be drawn from the HAGOS data, and further confirmation with larger numbers is required.

Unlike for patellar and Achilles tendinopathy, the proposed mechanism of effect for the HVIGI is not disruption of neovascularisation, nor is it likely to be disruption of scar tissue as none was visualised on ultrasound $12,13,15$. It is however hypothesised that the injectate lifts the periosteum, causing a local reaction which stimulates a healing response. This mechanistic theory requires further study. It has also been hypothesised that the chemical effects of Marcaine may cause some local denervation so that pain is diminished. Further radiological studies such as magnetic resonance imaging, and also surgical examination, may be useful to evaluate the potential mechanism of the injection. Whatever the underlying mechanism it is believed that the rehabilitation programme is required to ensure long term benefit and to decrease the risk of recurrence. 
It remains unclear as to why some patients have a good response to the HVIGI\&SR, while others experience little or no effect. When one is considering HVIGI\&SR, adherence to the rehabilitation programme is likely to be important in the overall outcome, along with other psychosocial factors such as pain beliefs and everyday use of the hip, for example at work. Future studies would therefore benefit from establishing patients' experiences of a HVIGI\&SR, especially in comparison to other treatment modalities. Also, GTPS covers so many pathologies that it may be some respond better than others and again this requires further investigation, with other imaging modalities perhaps being useful in assessing which conditions will benefit more from such an injection ${ }^{3-5}$. One suggestion is to use MRI pre-HVIGI and follow the subsequent changes to soft tissues and the bone on MRI over a suitable follow-up period, to allow clinicians to visualise the effects on the soft tissue and to establish whether certain initial changes seen on MRI predict the responsive to the HVIGI\&SR. This would allow the HVIGI\&SR to be targeted to those in whom it is likely to be clinically effective. The side effects of pain and stiffness described by the subjects are similar to the findings in a study that used steroid injections in GTPS $^{8}$. With this being a temporary phenomenon and with the lack of any other side effects a HVIGI\&SR in GTPS can provisionally be considered safe subject to confirmation in larger cohort controlled studies.

\section{Study Limitations}

The main limitation of this study was the size of the study, despite having both the retrospective and prospective data. This is especially noticeable within the prospective group and a longer recruitment period would be beneficial in the future. A sample size calculation using an $80 \%$ power and $5 \%$ significance suggests a sample size of 16 is required to show significance, 10 more than in this study ${ }^{25}$. It should however be noted that the majority of patients attending the had already failed conservative management, as shown in Table 2 by the number of clinicians patients had seen prior to their injection, and this is likely to affect the ability to recruit patients as it is normally a tertiary referral for the HVIGI\&SR.

The follow up time of just over six weeks in the prospective group is also not ideal, especially as the majority of the subjects had experienced pain for over two years. However, the retrospective follow-up at 60 weeks appears to show maintenance of the pain relieving effect, with $62 \%$ of the retrospective subjects reporting that they had returned to their normal level of activities. This is in contrast to a study which showed that the effect of a local corticosteroid injection alone declined after 1 month $^{8}$, therefore suggesting that the HVIGI\&SR combination avoids this decline. Out of the retrospective subjects only three had an additional treatment; 2 underwent surgery and 1 had acupuncture suggesting the majority responded to the HVIGI and physiotherapy rehabilitation alone. It seems there- fore likely that the findings in the prospective group would be maintained, although confirmation of this is required. It would also be useful to study whether adherence to the physiotherapy programme improved the outcomes associated with the HVIGI as it is likely that the injection primarily allows a pain-free period in which to start the rehabilitation programme correctly.

\section{Future Research}

As described above, further research is required to determine the mechanism of action of the HVIGI\&SR in GTPS. More work is also required to establish the duration of the effect of a HVIGI\&SR in GTPS. Anecdotally, 8 of the patients had more than one HVIGI. A randomised control trial would be the gold standard to establish the effects of the HVIGI\&SR, although in the short term a larger prospective study would be beneficial.

\section{Conclusions}

A high volume image guided injection into the periosteum of the greater trochanter followed by a structured physiotherapy-led rehabilitation programme should be considered as an effective treatment in the short and medium term for GTPS, when conservative measures have previously failed. Further controlled studies are warranted to conclusively determine the long-term effects of a HVIGI\&SR, along with comparison to other treatment modalities.

\section{References}

1. Bierma-Zeinstra S, Bohnen A, Ginai A, Prins A, Verhaar J. Validity of American College of Rheumatology criteria for diagnosing hip osteoarthritis in primary care research. J Rheumatol. 1999;26:1129-1133.

2. Blank E, Owens BD, Burks R, Belmont PJ Jr. Incidence of Greater Trochanteric Pain Syndrome in Active Duty US Military Servicemembers. Orthopedics. 2012;35:E1022-E1027.

3. Tortolani PJ, Carbone JJ, Quartararo LG. Greater trochanteric pain syndrome in patients referred to orthopedic spine specialists. Spine J. 2002;2:251-254.

4. Strauss EJ, Nho SJ, Kelly BT. Greater trochanteric pain syndrome. Sports Med Arthrosc. 2010;18:113-119.

5. Alvarez-Nemegyei J, Canoso JJ. Evidence-based soft tissue rheumatology - III: Trochanteric bursitis. J Clin Rheumatol. 2004;10:123-124.

6. Del Buono A, Papalia R, Khanduja V, Denaro V, Maffulli N. Management of the greater trochanteric pain syndrome: a systematic review. Br Med Bull. 2012;102:115-131.

7. Chowdhury R, Naaseri S, Lee J, Rajeswaran G. Imaging and management of greater trochanteric pain syndrome. Postgrad Med J. 2014;90:576-581.

8. Rompe JD, Segal NA, Cacchio A, Furia JP, Morral A, Maffulli N. Home Training, Local Corticosteroid Injection, or Radial Shock Wave Therapy for Greater Trochanter Pain Syndrome. Am J Sports Med. 2009;37:1981-1990.

9. McEvoy JR, Lee KS, Blankenbaker DG, del Rio AM, Keene JS. Ultrasound-Guided Corticosteroid Injections for Treatment of Greater Trochanteric Pain Syndrome: Greater Trochanter 
Bursa Versus Subgluteus Medius Bursa. AJR Am J Roentgenol. 2013;201:W313-W317.

10. Sayegh F, Potoupnis M, Kapetanos G. Greater trochanter bursitis pain syndrome in females with chronic low back pain and sciatica. Acta Orthop Belg. 2004;70:423-428.

11. Fearon AM, Cook JL, Scarvell JM, Neeman T, Cormick W, Smith PN. Greater Trochanteric Pain Syndrome Negatively Affects Work, Physical Activity and Quality of Life: A Case Control Study. J Arthroplasty. 2014;29:383-386.

12. Crisp T, Khan F, Padhiar N, Morrissey D, King J, Jalan R, Maffulli N, Chan O. High volume ultrasound guided injections at the interface between the patellar tendon and Hoffa's body are effective in chronic patellar tendinopathy: A pilot study. Disabil Rehabil. 2008;30:1625-1634.

13. Chan O, O'Dowd D, Padhiar N, Morrissey D, King J, Jalan R, Maffulli N, Crisp T. High volume image guided injections in chronic Achilles tendinopathy. Disabil Rehabil. 2008;30:1697-1708.

14. Morton S, Chan O, King J, Perry D, Crisp T, Maffulli N, Morrissey D. High volume image-guided injections for patellar tendinopathy: a combined retrospective and prospective case series. MLTJ. 2014;4:214-219.

15. Morton S, Ghozlan A, Price J, Chan O, Morrissey D. High volume image guided injection: useful in a rugby shoulder injury? Presented at XX11 International Conference on Sports Rehabilitation and Traumatology. 20th-21st April 2013. London.

16. Thorborg K, Holmich P, Christensen R, Petersen J, Roos EM. The Copenhagen Hip and Groin Outcome Score (HAGOS): development and validation according to the COSMIN checklist. Br J Sports Med. 2011;45:478-491.

17. Padulo J, Oliva F, Frizziero A, Maffulli N. Muscles, Ligaments and Tendons Journal. Basic principles and recommendations in clinical and field science research. MLTJ. 2013;4:250-252.

18. Cook JL, Purdam C. Is compressive load a factor in the development of tendinopathy? Br J Sports Med. 2012;46:163-168.

19. Mulligan EP, Middleton EF, Brunette M. Evaluation and management of greater trochanter pain syndrome. Phys Ther Sport. 2014. [Epub ahead of print]

20. Grimaldi A. Assessing lateral stability of the hip and pelvis. Man Ther. 2011;16:26-32.

21. Reiman MP, Thorborg K. Clinical examination and physical assessment of hip joint-related pain in athletes. Int J Sports Phys Ther. 2014;9:737-755.

22. Kelly AM. Does the clinically significant difference in visual analog scale pain scores vary with gender, age, or cause of pain? Acad Emerg Med. 1998;5:1086-1090.

23. Furia JP, Rompe JD, Maffulli N. Low-Energy Extracorporeal Shock Wave Therapy as a Treatment for Greater Trochanteric Pain Syndrome. Am J Sports Med. 2009;37:1806-1813.

24. Shbeeb MI, Oduffy JD, Michet CJ, Ofallon WM, Matteson EL. Evaluation of glucocorticosteroid injection for the treatment of trochanteric bursitis. J Rheumatol. 1996;23:2104-2106.

25. DSS Research. Sample Size Calculators. 2014. [Website]. Available at: https://www.dssresearch.com/KnowledgeCenter/toolkitcalculators/samplesizecalculators.aspx. 


\section{Appendix 1. Questionnaires administered.}

\section{Questionnaire for Retrospective Study}

\section{Reference Code:}

Date:

1. Age (in years)

18-25

26-35

$36-45$

46-55

$56-65$

66-75

$76-80$

$81+$

2. Gender

Male

Female

3. What sports/exercise do you take part in? (please list)

4. To what level do you participate? (please state for each sport/exercise)

For own enjoyment/fitness

Club level

Regional level

National/international level

Amateur

Semi-professional

Professional

5. How many hours/week of sport/exercise did you participate in before your hip pain started?

Less than 5 hours

5-10 hours

11-15 hours

16-20 hours

More than 20 hours

6. How many hours/week of sport/exercise did you participate in after your hip pain started?

Less than 5 hours

5-10 hours

11-15 hours

16-20 hours

More than 20 hours

7. Which is your dominant side (ie left or right handed)?

Left

Right

8. What is the diagnosis given for your hip pain?

Bursitis

Tendinopathy 


\section{S. Morton et al.}

\section{Appendix 1. (cont.)}

\section{Questionnaire for Retrospective Study}

\section{Muscle tear}

Greater Trochanter Pain Syndrome

You are unsure of the diagnosis but you have been given one

Doctor/physio is unsure of diagnosis

Other (please state):

9. Please describe the mechanism of injury (how it occurred)

10. How long did you have hip pain before the high volume injection?

Less than 6 months

More than 6 months, less than 12 months

More than 12 months, less than 18 months

More than 18 months, less than 2 years

More than 2 years (please state)

11. Do you have other medical conditions or previous operations? (please list)

12. How many clinicians have you seen with your hip pain? (state number of each)

\begin{tabular}{l}
\hline Doctor \\
\hline Physiotherapist \\
\hline Surgeon \\
\hline Osteopath \\
\hline Masseur \\
\hline Other (please state)
\end{tabular}

13. Which investigations have you received for your hip pain? (please tick all that apply)

\begin{tabular}{l}
\hline Blood tests \\
\hline XRay \\
\hline CT scan \\
\hline MRI scan \\
\hline Ultrasound scan \\
\hline Other (please state)
\end{tabular}

14. Which treatments for your hip pain did you use before the high volume injection? (please tick all that apply)

\section{Oral painkillers}

Topical painkillers

Physiotherapy

Steroid injection (please state number)

Shock wave therapy (please state number)

Surgery

Other (please state):

\section{Following the injection:}

15. Did you experience any side effects of the high volume injection?

$$
\begin{aligned}
& \text { Yes } \\
& \hline \text { No }
\end{aligned}
$$




\section{Appendix 1. (cont.)}

\section{Questionnaire for Retrospective Study}

If yes, please state side effects

16. Have you been able to carry out the exercise programme as advised by the physiotherapist?

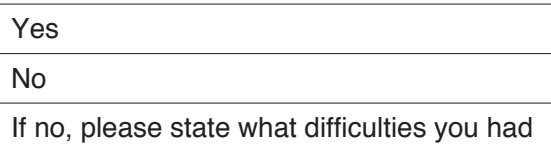

17. Have you received any other treatments for your hip pain since the high volume injection?

\begin{tabular}{l} 
Yes \\
No \\
If yes, please state which treatments \\
\hline 18. How many hours/week of sport/exercise are you currently participating in? \\
\hline Less than 5 hours \\
\hline $5-10$ hours \\
\hline $11-15$ hours \\
\hline $16-20$ hours \\
\hline More than 20 hours \\
\hline 19. Have you returned to your normal activities (regardless of current level of ability)? \\
\hline Yes \\
\hline No \\
\hline 20. Have you returned to your normal level of ability? \\
\hline Yes \\
\hline No
\end{tabular}

21. Any other comments:

\section{For practitioner to complete:}

Date of HVI:

Volume and content of injection:

\section{Level of pain}

Please mark with a cross on the line your level of pain during everyday activities before having the high volume injection.

No Pain

Max Pain

Please mark with a cross on the line your current level of pain during everyday activities.

No Pain

\section{Initial Patient Questionnaire for Prospective Study}

\section{Reference Code:}

Date:

1. Age (in years)

18-25

26-35

36-45

46-55

$56-65$

66-75

$76-80$

(to be continued) 


\section{S. Morton et al.}

\section{Appendix 1. (cont.)}

\section{Initial Patient Questionnaire for Prospective Study}

$$
81+
$$

\section{Gender}

$$
\text { Male }
$$

Female

\section{Height}

\section{Weight}

5. What sports/exercise do you take part in? (Please list)

6. To what level do you participate? (please state for each sport/exercise)

For own enjoyment/fitness

Club level

Regional level

National/international level

Amateur

Semi-professional

Professional

7. How many hours/week of sport/exercise did you participate in before your hip pain started?

Less than 5 hours

5-10 hours

11-15 hours

16-20 hours

More than 20 hours

8. How many hours/week of sport/exercise have you participated in since your hip pain started?

Less than 5 hours

5-10 hours

11-15 hours

16-20 hours

More than 20 hours

9. Which is your dominant side (i.e. left or right handed)?

Left

Right

10. What is the diagnosis given for your hip pain?

Bursitis

Tendinopathy

Muscle tear

Greater Trochanter Pain Syndrome

You are unsure of the diagnosis but you have been given one

Doctor/physio is unsure of diagnosis

Other (please state):

11. Please describe the mechanism of injury (how it occurred)

12. How long have you had your hip pain?

Less than 6 months 


\section{Appendix 1. (cont.)}

\section{Initial Patient Questionnaire for Prospective Study}

More than 6 months, less than 12 months

More than 12 months, less than 18 months

More than 18 months, less than 2 years

More than 2 years (please state)

13. Do you have other medical conditions or previous operations? (Please list)

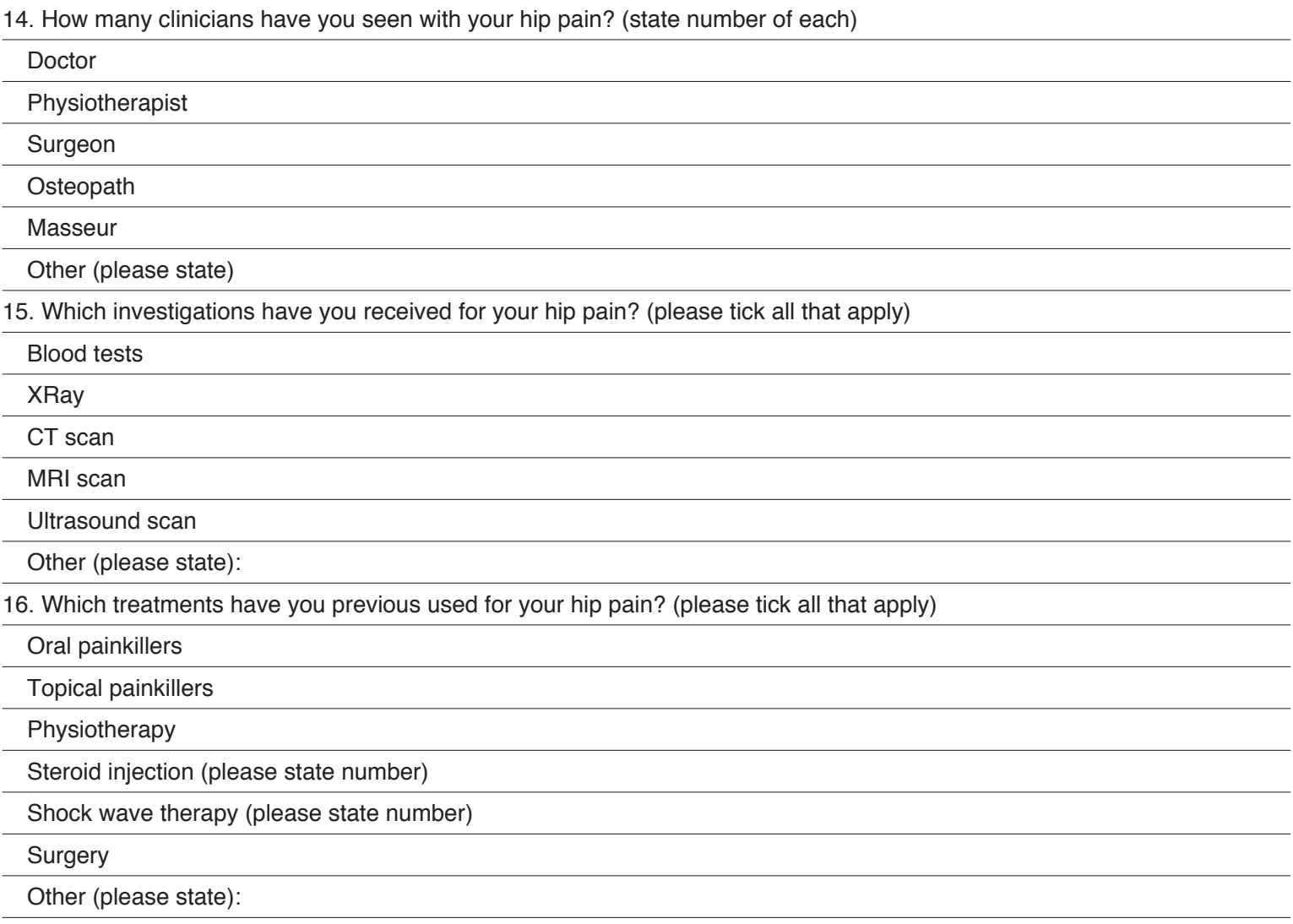

17. Any other comments:

\section{For practitioner to complete:}

Date of HVI:

Volume and content of injection:

\section{Current level of pain}

Please mark with a cross on the line your current level of pain during everyday activities.

No Pain

\section{Follow-up Patient Questionnaire for Prospective Study}

\section{Reference Code:}

Date:

1. Did you experience any side effects of the high volume injection?

Yes 


\section{S. Morton et al.}

\section{Appendix 1. (cont.)}

\section{Initial Patient Questionnaire for Prospective Study}

No
If yes, please state side effects

2. Have you been able to carry out the exercise programme as advised by the physiotherapist?

Yes

\section{No}

If no, please state what difficulties you had

3. Have you received any other treatments for your hip pain since the high volume injection?

\begin{tabular}{l} 
Yes \\
\hline No \\
\hline If yes, please state which treatments
\end{tabular}

4. How many hours/week of sport/exercise are you currently participating in?

\begin{tabular}{l}
\hline Less than 5 hours \\
\hline $5-10$ hours \\
\hline $11-15$ hours \\
\hline $16-20$ hours \\
\hline More than 20 hours \\
\hline 5. Have you returned to your normal activities (regardless of current level of ability)? \\
\hline Yes \\
\hline No \\
\hline 6 . Have you returned to your normal level of ability? \\
\hline Yes \\
No
\end{tabular}

7. Any other comments:

\section{Current level of pain}

Please mark with a cross on the line your current level of pain during everyday activities.

No Pain — Max Pain

\section{Appendix 2. HAGOS questionnaire used for prospective subjects:}

\section{HAGOS}

Questionnaire concerning hip and/or groin problems

Today's date:

Reference Code:

INSTRUCTIONS: this questionnaire asks for your view about your hip and/or groin

problem. The questions should be answered considering your hip and/or groin function during the past week. This information will help us keep track of how you feel, and how well you are able to do your usual activities.

Answer every question by ticking the appropriate box. Tick only one box for each

question. If a question does not pertain to you or you have not experienced it in the past week please make your "best guess" as to which response would be the most accurate.

\section{Symptoms}

These questions should be answered considering your hip and/or groin symptoms and difficulties during the past week. 
Appendix 2. (cont.)

S1 Do you feel discomfort in your hip and/or groin?

$\begin{array}{llll}\text { Never } & \text { Rarely } & \text { Sometimes } & \text { Often }\end{array}$

$\begin{array}{llll}\square & \square & \square & \square\end{array}$

S2 Do you hear clicking or any other type of noise from your hip and/or groin?

$\begin{array}{lllll}\text { Never } & \text { Rarely } & \text { Sometimes } & \text { Often } & \text { All the time } \\ \square & \square & \square & \square & \square\end{array}$

S3 Do you have difficulties stretching your legs far out to the side?

None Mild $\quad$ Moderate $\quad$ Severe $\quad$ Extreme

S4 Do you have difficulties taking full strides when you walk?

None Mild $\quad$ Moderate $\quad$ Severe

S5 Do you experience sudden twinging/stabbing sensations in your hip and/or groin?

Never Rarely Sometimes Often the time

$\begin{array}{llll}\square & \square & \square & \square\end{array}$

\section{Stiffness}

The following questions concern the amount of stiffness you have experienced during the past week in your hip and/or groin. Stiffness is a sensation of restriction or slowness in the ease with which you move your hip and/or groin.

S6 How severe is your hip and/or groin stiffness after first awakening in the morning?

None Mild $\quad$ Moderate $\quad$ Severe $\quad$ Extreme

S7 How severe is your hip and/or groin stiffness after sitting, lying or resting later in the day?

None Mild Moderate Severe Extreme

Pain

P1 How often is your hip and/or groin painful?

$\begin{array}{lllll}\text { Never } & \text { Monthly } & \text { Weekly } & \text { Daily } & \text { Always } \\ \square & \square & \square & \square & \square\end{array}$

P2 How often do you have pain in areas other than your hip and/or groin that you think may be related to your hip and/or groin problem?
Never
Monthly
Weekly
Daily
Always

The following questions concern the amount of pain you have experienced during the past week in your hip and/or groin. What amount of hip and/or groin pain have you experienced during the following activities?

\begin{tabular}{|c|c|c|c|c|}
\hline \multicolumn{5}{|c|}{ P3 Straightening your hip fully } \\
\hline None & Mild & Moderate & Severe & Extreme \\
\hline$\square$ & $\square$ & $\square$ & $\square$ & $\square$ \\
\hline \multicolumn{5}{|c|}{ P4 Bending your hip fully } \\
\hline None & Mild & Moderate & Severe & Extreme \\
\hline$\square$ & $\square$ & $\square$ & $\square$ & $\square$ \\
\hline \multicolumn{5}{|c|}{ P5 Walking up or down stairs } \\
\hline None & Mild & Moderate & Severe & Extreme \\
\hline$\square$ & $\square$ & $\square$ & $\square$ & $\square$ \\
\hline
\end{tabular}

P6 At night while in bed (pain that disturbs your sleep)

$\begin{array}{lllll}\text { None } & \text { Mild } & \text { Moderate } & \text { Severe } & \text { Extreme } \\ \square & \square & \square & \square & \square\end{array}$

(to be continued) 
Appendix 2. (cont.)

P7 Sitting or lying

None Mild Moderate Severe $\quad$ Extreme

The following questions concern the amount of pain you have experienced during the past week in your hip and/or groin. What amount of hip and/or groin pain have you experienced during the following activities?

P8 Standing upright

$\begin{array}{lllll}\text { None } & \text { Mild } & \text { Moderate } & \text { Severe } & \text { Extreme } \\ \square & \square & \square & \square & \square\end{array}$

P9 Walking on a hard surface (asphalt, concrete, etc.)

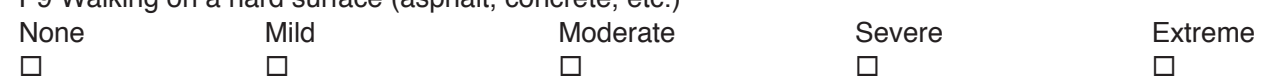

P10 Walking on an uneven surface

$\begin{array}{lllll}\text { None } & \text { Mild } & \text { Moderate } & \text { Severe } & \text { Extreme } \\ \square & \square & \square & \square & \square\end{array}$

\section{Physical function, daily living}

The following questions concern your physical function. For each of the following activities please indicate the degree of difficulty you have experienced in the past week due to your hip and/or groin problem.

A1 Walking up stairs
None
Mild
Moderate
Severe
Extreme

A2 Bending down, e.g. to pick something up from the floor

None Mild Moderate $\quad$ Severe

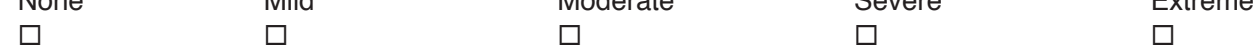

A3 Getting in/out of car

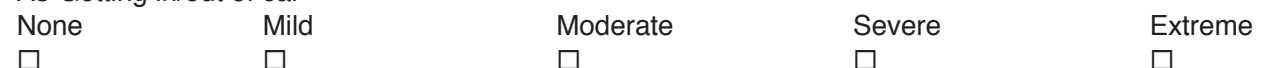

A4 Lying in bed (turning over or maintaining the same hip position for a long time)

None Mild $\quad$ Moderate $\quad$ Severe $\quad$ Extreme

A5 Heavy domestic duties (scrubbing floors, vacuuming, moving heavy boxes etc.)

$\begin{array}{llll}\text { None } & \text { Mild } & \text { Moderate } & \text { Severe }\end{array}$

\section{Function, sports and recreational activities}

The following questions concern your physical function when participating in higher-level activities. Answer every question by ticking the appropriate box. If a question does not pertain to you or you have not experienced it in the past week please make your "best guess" as to which response would be the most accurate. The questions should beanswered considering what degree of difficulty you have experienced during thefollowing activities in the past week due to problems with your hip and/or groin.

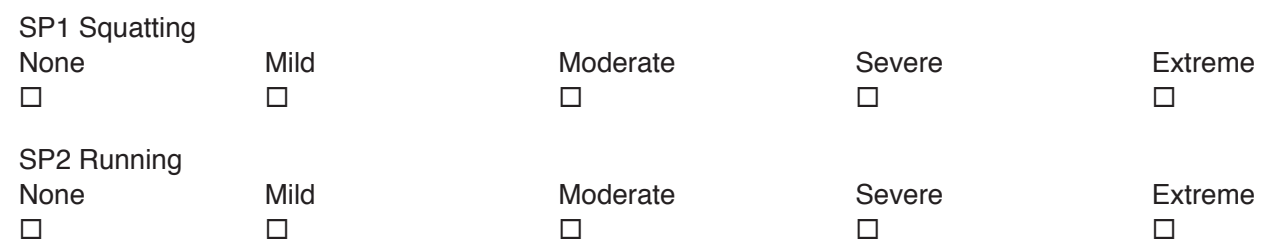

SP3 Twisting/pivoting on a weight bearing leg

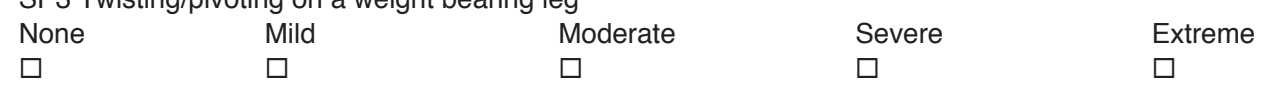


Appendix 2. (cont.)

SP4 Walking on an uneven surface

None Mild $\quad$ Moderate $\quad$ Severe $\quad$ Extreme

SP5 Running as fast as you can

None Mild $\quad$ Moderate $\quad$ Severe $\quad$ Extreme

SP6 Bringing the leg forcefully forward and/or out to the side, such as in kicking, skating etc.

None Mild Moderate $\quad$ Severe

$\begin{array}{llll}\square & \square & \square & \square\end{array}$

SP7 Sudden explosive movements that involve quick footwork, such as accelerations, decelerations, change of directions etc. None Mild Moderate Severe Extreme

SP8 Situations where the leg is stretched into an outer position (such as when the leg is placed as far away from the body as possible)
None
Mild
Moderate
Severe
Extreme

\section{Participation in physical activities}

The following questions are about your ability to participate in your preferred physical activities. Physical activities include sporting activities as well as all other forms of activity where you become slightly out of breath. When you answer these questions considerto what degree your ability to participate in physical activities during the past weekhas been affected by your hip and/or groin problem.

PA1 Are you able to participate in your preferred physical activities for as long as you would like?
Always
Often
Sometimes
Rarely
Never

PA2 Are you able to participate in your preferred physical activities at your normal performance level?

$\begin{array}{lllll}\text { Always } & \text { Often } & \text { Sometimes } & \text { Rarely } & \text { Never } \\ \square & \square & \square & \square & \square\end{array}$

\section{Quality of Life}

Q1 How often are you aware of your hip and/or groin problem?
Never
Monthly
Weekly
Daily
Constantly

Q2 Have you modified your life style to avoid activities potentially damaging to your hip and/or groin?

Not at all Mildy

Mildly Moderately

Severely Totally

Q3 In general, how much difficulty do you have with your hip and/or groin?

None $\quad$ Mild $\quad$ Moderate $\quad$ Severe $\quad$ Extreme

Q4 Does your hip and/or groin problem affect your mood in a negative way?

$\begin{array}{llll}\text { Not at all } & \text { Rarely } & \text { Sometimes } & \text { Often All the time }\end{array}$

Q5 Do you feel restricted due to your hip and/or groin problem?

Not at all Rarely

Sometimes Often All the time

Thank you very much for completing all the questions in this questionnaire. 